\title{
Radiosensitization effects of curcumin plus cisplatin on non-small cell lung cancer A549 cells
}

\author{
YONG CAI, ZHAOYING SHENG and SHIXIONG LIANG \\ Department of Radiation Oncology, Shanghai Pulmonary Hospital, \\ Tongji University School of Medicine, Shanghai 200433, P.R. China
}

Received January 8, 2016; Accepted July 27, 2017

DOI: $10.3892 /$ ol.2019.10364

\begin{abstract}
The aim of the present study was to determine the radiosensitization effect of the combination of curcumin and cisplatin on non-small cell lung cancer (NSCLC) A549 cells. Cell viability was analyzed using the MTT assay following treatment with different concentrations of curcumin and cisplatin for 24 72 h. Survival fraction (SF) value of the treatment groups (single irradiation, curcumin + irradiation, cisplatin + irradiation, and curcumin + cisplatin + irradiation) treated with different doses of X-ray radiation were evaluated using colony formation assay, according to a multi-target single-hit model. Migration and invasion as well as the levels of epidermal growth factor receptor (EGFR) protein following $24 \mathrm{~h}$ were detected by scratch wound assay, Matrigel assay and western blot analysis, respectively. The results of the present study demonstrated that the viability of the cells decreased after being treated by curcumin, and the inhibitory effect was dose and time-dependent as the concentration of curcumin increased from 10 to $200 \mu \mathrm{mol} / 1$ $(\mathrm{P}<0.05)$. SF value was lower in the curcumin + cisplatin + irradiation group compared with the other three treatment groups at 2 10 Gy. Furthermore, SF value was lower in the curcumin + irradiation group at $4 \sim 10 \mathrm{~Gy}$. The SF value was also lower in the cisplatin + irradiation group at 2 10 Gy compared with the single irradiation group $(\mathrm{P}<0.05)$. The sensitization enhancement ratios in the curcumin + irradiation, cisplatin + irradiation, and curcumin + cisplatin + irradiation groups were $1.24,1.31$ and 1.96 , respectively. The migration distance, the number of cells invaded through the transmembrane, and the level of EGFR protein in four treatment groups were the highest in the single irradiation group, compared with the other three treatment groups $(\mathrm{P}<0.05)$. Furthermore, the radiosensitization effects of
\end{abstract}

Correspondence to: Dr Shixiong Liang, Department of Radiation Oncology, Shanghai Pulmonary Hospital, Tongji University School of Medicine, 507 Zhengmin Road, Shanghai 200433, P.R. China E-mail: shixiongliang898@sina.com

Key words: curcumin, cisplatin, radiosensitization, epidermal growth factor receptor curcumin and cisplatin on NSCLC A549 cells, which include inhibition of proliferation, migration and invasion, may be associated with the inhibition of the EGFR-associated signaling pathway.

\section{Introduction}

Lung cancer has the highest levels of morbidity and mortality of all malignant tumors globally, of which $80-85 \%$ patients are non-small cell lung cancer (NSCLC) (1). NSCLC includes squamous cell carcinoma, adenocarcinoma, and large cell carcinoma. Compared with small cell carcinoma, NSCLC has a relatively slow growth rate and relatively late on-set of metastasis. Common symptoms of NSCLC include coughing, hemoptysis, chest pain, chest tightness and dyspnea. In recent years, radiotherapy has become the most common method for treating lung cancer and has an increasing role in treating patients with recurrent lung cancer who are unable to undergo surgery. Unlike small cell lung cancer (SCLC), non-small cell lung cancer (NSCLC) is insensitive to radiotherapy and has a low response rate. Therefore, the overall therapeutic effect is unsatisfactory $(2,3)$. Therefore, knowing how to improve the therapeutic effect of radiotherapy is of great significance, and radiosensitization has become a major focus in the field of radiotherapy. Furthermore, researchers in and outside of China are currently searching and testing different methods of radiosensitization. Curcumin is a phenolic compound extracted from the rootstocks of multiple traditional Chinese medicines (TCMs), and multiple biological activities of curcumin have been reported, including antihypertensive and anti-hyperlipidemic effects, oxidation resistance and immunoregulation (4-6). In recent years, it has been reported that curcumin has multiple anti-tumor activities, including inhibiting proliferation and inducing cell apoptosis in tumors (7-9). Cisplatin is a common chemotherapeutic agent for lung cancer. A previous study has demonstrated that treatment with a combination of curcumin and cisplatin is able to inhibit proliferation and induce apoptosis in lung cancer (10). However, whether or not curcumin has a radiosensitization effect on NSCLC tumors is not clear, and to the best of our knowledge has not been demonstrated previously. Therefore, the present study was conducted to determine the radiosensitization effect of a combination of curcumin and cisplatin on the treatment of NSCLC A549 cells. 


\section{Materials and methods}

Key reagents and instruments. Curcumin and DMSO were purchased from Sigma-Aldrich, (Merck KGaA, Darmstadt, Germany). NSCLC A549 cells were purchased from the Chinese Academy of Sciences (Shanghai, China). Trypsin and RPMI-1640 medium were obtained from Gibco (Thermo Fisher Scientific, Inc., Waltham, MA, USA) and methyl thiazolyl tetrazolium (MTT) was purchased from Beyotime Institute of Biotechnology (Haimen, China). Rabbit anti-epidermal growth factor receptor (EGFR) polyclonal (1:1,000; cat. no. 1721100) and rabbit anti-GADPH (1:2,000; cat. no. 1721011) were purchased from Santa Cruz Biotechnology, Inc. (Dallas, TX, USA), and newborn calf serum was purchased from Hangzhou Sijiqing Biological Engineering Materials Co.,Ltd. (Hangzhou, China). The $\mathrm{CO}_{2}$ incubator with thermostat, medical linear accelerator, automatic enzyme standard instrument (ELX800; Omega Bio-Tek, Inc., Norcross, GA, USA), Hoefer mini-VE, ECL chemiluminescence reagent (PerkinElmer, Inc., Waltham, MA, USA), and nitrocellulose membranes (Omega Bio-Tek, Inc.) were also used.

Cell culture. A549 cells were inoculated into RPMI-1640 medium containing $15 \%$ fetal bovine serum (FBS; Thermo Fisher Scientific, Inc.), and the cells were put into the incubator with a saturated humidity of $5 \% \mathrm{CO}_{2}$ at $37^{\circ} \mathrm{C}$. Adherent cells grew well and were sub-cultured every 3 days. The cells in the logarithmic phase were used for subsequent experiments.

Irradiation conditions. An electron linear accelerator was used for irradiating cells in cell culture plates with a water tank below (height, $5 \mathrm{~cm}$ ) and a tissue glue above (thickness, $\sim 1.5 \mathrm{~cm}$ ) the plates. The source-target distance was $100 \mathrm{~cm}$, and $6 \mathrm{MV}-\mathrm{X}$ ray irradiation was administered under a $10 \times 10 \mathrm{~cm}$ irradiation field, with a $200 \mathrm{cGy} / \mathrm{min}$ dose rate. The cells were irradiated by different doses of X-ray (0-10 Gy) according to experimental requirements and then cultured in the incubator with a saturated humidity of $5 \% \mathrm{CO}_{2}$ at $37^{\circ} \mathrm{C}$ for $24 \mathrm{~h}$.

MTT assay. The cells in the logarithmic phase were inoculated into 96 -well culture plates at a concentration of $6.0 \times 10^{7} / 1$ $(100 \mu \mathrm{l} /$ well $)$ and cultured in a $5 \% \mathrm{CO}_{2}$ incubator at $37^{\circ} \mathrm{C}$ for $24 \mathrm{~h}$. Different doses of curcumin (10, 20, 50, 100 and $200 \mu \mathrm{mol} / \mathrm{l})$ and cisplatin $(1,2,5,10$ and $20 \mathrm{mg} / \mathrm{l})$ were added to the culture plates following cell confluence. Cell cultures without curcumin or cisplatin were regarded as control groups, while the other cell cultures were the experimental groups. Following cultivation of the cells at $37^{\circ} \mathrm{C}$ for 24,48 and $72 \mathrm{~h}, 20 \mu 1$ MTT $(2 \mathrm{~g} / \mathrm{l})$ was added to each well and cultured for another $4 \mathrm{~h}$ until cultivation was terminated. After the culture solution was removed, $150 \mu \mathrm{l}$ DMSO was added to each well and shaken for $10 \mathrm{~min}$. The absorbance value (ABS) of each well was determined by the microplate reader at a wavelength of $490 \mathrm{~nm}$. A total of 6 parallel replicate wells were used for each concentration, and the experiment was repeated three times. The following formula was used to calculate cell viability: Cell viability=(ABS in experimental group/ABS in control group) $\times 100 \%$.

Colony formation experiment. According to the MTT results, concentrations of curcumin $(10 \mu \mathrm{mol} / \mathrm{l})$ and cisplatin
$(1 \mathrm{mg} / \mathrm{l})$ with mild cytotoxicity were selected for subsequent experiments. Single-cell suspensions of A549 cells in the logarithmic phase were produced and inoculated into 24-well plates at 200 cells/well. Each plate included the following four groups: Single irradiation, curcumin + irradiation, cisplatin + irradiation, and curcumin + cisplatin + irradiation. After $24 \mathrm{~h}$ of transfection, the cells were irradiated by different doses of X-ray $(0,2,4,6,8$ and $10 \mathrm{~Gy})$ for another 10 days of cultivation, fixed with absolute ethyl alcohol for $15 \mathrm{~min}$ and stained with $0.1 \%$ crystal violet for $20 \mathrm{~min}$. The number of clones $>50$ was counted under an inverted microscope in order to calculate the cloning efficiency $(\mathrm{CE})$, as follows: $\mathrm{CE}(\%)=($ mean clone formation for the treatment group/inoculated cell number) $\mathrm{x} 100 \%$. Surviving fraction $(\mathrm{SF})=(\mathrm{CE}$ in the irradiated group/CE in the non-irradiated group) $\mathrm{x} 100 \%$. The experiments were repeated three times for calculating the average value.

According to the multi-target single-hit model $\left[\mathrm{SF}=1-\left(1-\mathrm{e}^{-\mathrm{D} / \mathrm{D} 0}\right)^{\mathrm{N}}\right]$, a cell survival curve was drawn for calculating the sensitization enhancement ratio (SER). The equation for SER is as follows: $S E R=D_{0}$ in the control group $/ \mathrm{D}_{0}$ in the experimental group. Based on the equation, $\mathrm{D}_{0}$ refers to the required dose of the curve index reduced by $63 \%\left(\mathrm{D}_{0}=1 / \mathrm{k}\right)$, and $\mathrm{D}_{\mathrm{q}}$ refers to the threshold dose of cell damage $\left(\mathrm{D}_{\mathrm{q}}=\mathrm{D}_{0}\right.$. $\ln \mathrm{N})$. The experiment was repeated three times.

Scratch wound assay. A549 cells in the four treatment groups were inoculated into 96 -well plates at a density of $1 \times 10^{5} / \mathrm{ml}$ and irradiated with 4 Gy X-ray. The cells formed into a cell monolayer. A line was drawn along the bottom of the culture plate using a pipette tip. The marginal area and relative distance of the scratch was captured and determined under an inverted microscope. After the culture solution was replaced with serum-free RPMI-1640 medium, the cells were cultured according to the requirements of the groups. Afterwards, an image of the area of the wounded region lacking cells was captured and calculated. Values of the area of the wounded region lacking cells prior to and following treatment were compared. The experiment was repeated three times.

Matrigel assay for assessing invasion. A Matrigel assay was performed by using a Transwell chamber (Qiagen $\mathrm{GmbH}$, Hilden, Germany) with pore size of $8.0 \mu \mathrm{m}$. The Transwell chamber was coated with $60 \mu \mathrm{l} 0.8 \%$ liquid Matrigel at $37^{\circ} \mathrm{C}$ for incubation 4-5 h. A549 cells in the four treatment groups irradiated by 4 Gy X-ray were inoculated into RPMI-1640 medium containing $15 \% \mathrm{FBS}$, and the cells were placed into an incubator with a saturated humidity of $5 \% \mathrm{CO}_{2}$ at $37^{\circ} \mathrm{C}$ for $24 \mathrm{~h}$. They were then washed three times with Dulbecco's modified Eagle's medium (Thermo Fisher Scientific, Inc.) and suspended in culture medium containing $10 \% \mathrm{FBS}\left(5 \times 10^{5} / \mathrm{ml}\right)$. The cell suspension $(200 \mathrm{ml})$ was added to the upper chamber of the Transwell chamber, and $600 \mathrm{ml}$ culture medium containing 10\% FBS was added into the lower chamber. Subsequently, the cells were cultured in a $5 \% \mathrm{CO}_{2}$ incubator at $37^{\circ} \mathrm{C}$ for $24 \mathrm{~h}$. The cells in the upper chamber were scrapped with a cotton swab then the culture medium containing $10 \%$ FBS was inverted, and dried at $37^{\circ} \mathrm{C}$ for $12 \mathrm{~h}$. The cells were put in a 24-well plate, which were stained with $0.1 \%$ crystal violet $(500 \mu \mathrm{l})$ were washed with phosphate buffer solution (PBS) following incubation at $37^{\circ} \mathrm{C}$ for $30 \mathrm{~min}$. A total of four 
visual fields were observed with a confocal microscope (x63 oil immersed optics; DC 300F, Leica Microsystems GmbH, Wetzlar, Germany), and images for calculating the number of cells that migrated across the membranes. The experiment was repeated three times.

Western blot analysis of signaling proteins. A549 cells in the four treatment groups irradiated with 4 Gy of X-rays and cultured for $24 \mathrm{~h}$ were added to RIPA lysis buffer (Hunan Sunshine Bio-Tech, Co., Ltd., Changsha, China) for $30 \mathrm{~min}$ and centrifuged at $12,000 \mathrm{r} / \mathrm{min}$ for $10 \mathrm{~min}$ at $37^{\circ} \mathrm{C}$ in a pre-cooled Eppendorf tube. The supernatant was collected for detection of protein concentration using Nanodrop 2000 spectrophotometer (Nanodrop Technologies; Thermo Fisher Scientific, Inc., Waltham, MA, USA). Then, an isopycnic loading buffer was re-added to the Eppendorf tube and bathed in boiling water for 5 min. Loading buffer $(20-50 \mu \mathrm{l})$ was added. The proteins were separated by $12 \%$ SDS polyacrylamide gel electrophoresis, initially at $80 \mathrm{~V}$ and then at $100 \mathrm{~V}$. The proteins were subsequently transferred into polyvinylidene difluoride membranes. Following incubation in $1 \%$ bovine serum albumin at room temperature for $2 \mathrm{~h}$, the appropriate primary rabbit antibodies (1:500; cat no. SC-1616; Santa Cruz Biotechnology, Inc.) were added. The membranes were incubated with the primary antibodies at room temperature for $2 \mathrm{~h}$ and with the secondary antibody (cat no. SC-2054; Santa Cruz Biotechnology, Inc.) at room temperature for $1 \mathrm{~h}$. The membrane was washed three times with Tris-buffered saline with Tween (TBST) for $5 \mathrm{~min}$. The membranes were visualized with electrochemiluminescence (ECL; cat no. NCI4106; Thermo Fisher Scientific, Inc.) reagent. A single group was performed three times with $\mathrm{X}$-film exposure, developed, and photographic fixed. GADPH was used as a loading control. The optical density of the target bands was detected using Image Pro Plus 6.0 software (Media Cybernetics, Inc., Rockville, MD, USA) and using the following equation: The final result=gray value of each band/internal reference.

Statistical data analysis. SPSS (version 13.0; SPSS, Inc., Chicago, IL, USA) was used for data analysis. The data are expressed as the mean \pm standard deviation. The differences between two groups were compared using a paired t-test, and the differences between multiple groups were compared using one-way analysis of variance with Tukey's test. $\mathrm{P}<0.05$ was considered to indicate a statistically significant difference.

\section{Results}

Inhibitory effect of curcumin on A549 NSCLC cells. As shown in Fig. 1, the viability of A549 cells was significantly decreased $(\mathrm{P}=0.037)$ following treatment with different concentrations of curcumin or cisplatin for $24 \mathrm{~h}$, and the inhibitory effect was dose and time-dependent. The $\mathrm{IC}_{20}$ values of curcumin and cisplatin on A549 cells were $15.74 \mu \mathrm{mol} / 1$ and $1.25 \mathrm{mg} / \mathrm{l}$, respectively. To reduce the toxic effects of curcumin and cisplatin on A549 cells in the radiosensitization experiments, $10 \mu \mathrm{mol} / 1$ curcumin and $1 \mathrm{mg} / \mathrm{l}$ cisplatin were used.

Inhibitory effect of X-ray irradiation on A549 cells following treatment with a combination of curcumin and cisplatin.
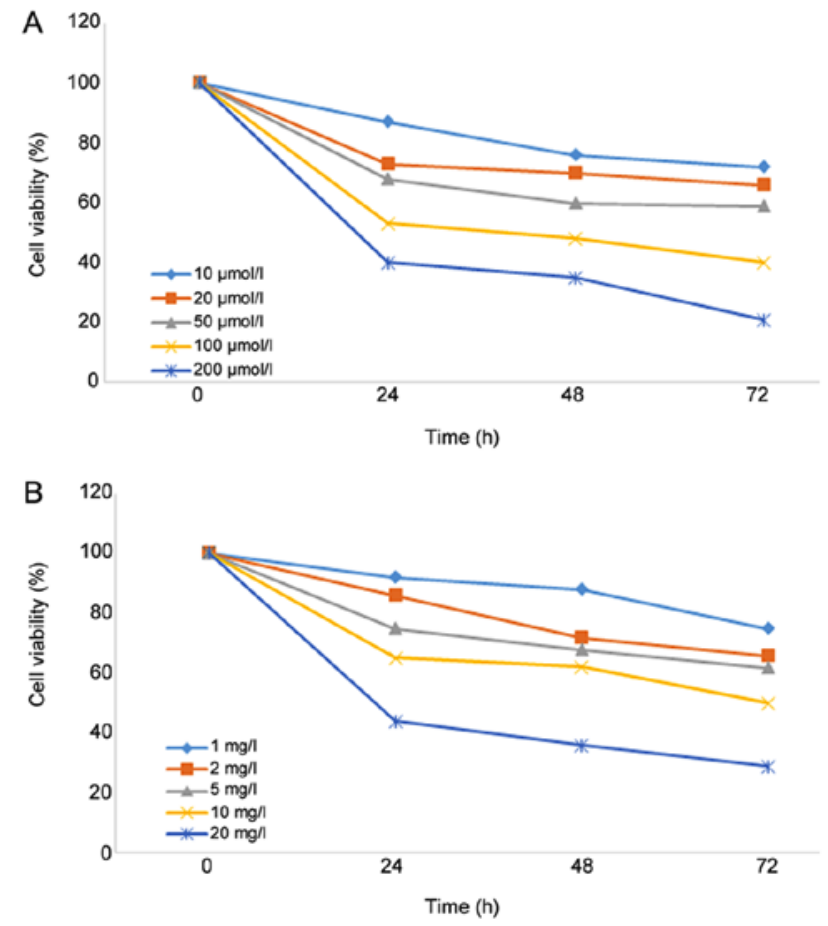

Figure 1. Effects of different concentrations of (A) curcumin and (B) cisplatin on the viability of A549 cells.

Following treatment with curcumin, cisplatin, or a combination of curcumin and cisplatin for $24 \mathrm{~h}, \mathrm{~A} 549$ cells were irradiated with different doses of X-rays (0, 2, 4, 6, 8 and $10 \mathrm{~Gy})$. It was demonstrated that SF value was lower in the curcumin + cisplatin + irradiation group compared with the other three treatment groups at 2 10 Gy. The SF value was lower in the curcumin + cisplatin + irradiation group compared with the curcumin + irradiation group at 4-10 Gy. The SF value was lower in the cisplatin + irradiation group compared with the single irradiation group 2-10 Gy $(\mathrm{P}<0.05$; Fig. 2). The SER values for the curcumin + irradiation, cisplatin + irradiation, and curcumin + cisplatin + irradiation groups were 1.24, 1.31 and 1.96, respectively (Table I and Fig. 2).

Inhibitory effects of $X$-ray irradiation on migration of $A 549$ cells following treatment with a combination of curcumin and cisplatin. The migration ratios in the curcumin + irradiation, cisplatin + irradiation, and curcumin + cisplatin + irradiation groups were $86.0 \pm 9.0,79.0 \pm 6.0$, and $37.0 \pm 5.0 \%$, respectively (Fig. 3) compared with the single irradiation group (1.00) $(\mathrm{P}<0.05$; Fig. 2).

Inhibitory effects of X-ray irradiation on invasion of A549 cells following treatment with a combination of curcumin and cisplatin. The number cells invaded through the membrane in the single irradiation, curcumin + irradiation, cisplatin + irradiation, and curcumin + cisplatin + irradiation groups were $521 \pm 21,352 \pm 17,229 \pm 12$, and $154 \pm 16$, respectively $(\mathrm{P}<0.05$; Fig. 4).

Inhibitory effects of X-ray irradiation on the expression of EGFR following treatment with a combination of curcumin and cisplatin. The levels of EGFR in the curcumin + irradiation, 
Table I. Survival values (\%) of A549 cells in four treatment groups irradiated by different doses of X-rays.

\begin{tabular}{lrrrcrc}
\hline & \multicolumn{7}{c}{ Radiation dose $(\mathrm{Gy})$} \\
\cline { 2 - 7 } Groups & \multicolumn{1}{c}{0} & 2 & 4 & 6 & 8 & 10 \\
\hline Single irradiation, mean \pm SD & $100.00 \pm 1.23$ & $91.10 \pm 1.69$ & $70.22 \pm 1.33$ & $52.25 \pm 1.74$ & $41.58 \pm 2.28$ & $17.08 \pm 1.93$ \\
Curcumin + irradiation, mean \pm SD & $95.01 \pm 3.21$ & $85.59 \pm 2.05$ & $56.35 \pm 1.91^{\mathrm{a}}$ & $35.40 \pm 2.03^{\mathrm{a}}$ & $19.04 \pm 1.53^{\mathrm{a}}$ & $9.61 \pm 2.24^{\mathrm{a}}$ \\
Cisplatin + irradiation, mean \pm SD & $97.82 \pm 2.04$ & $80.78 \pm 1.75^{\mathrm{a}}$ & $62.79 \pm 2.06^{\mathrm{a}, \mathrm{b}}$ & $41.49 \pm 1.24^{\mathrm{a}, \mathrm{b}}$ & $22.40 \pm 1.09^{\mathrm{a}, \mathrm{b}}$ & $12.09 \pm 1.76^{\mathrm{a}, \mathrm{b}}$ \\
Curcumin + cisplatin and irradiation, & $96.54 \pm 2.55$ & $72.78 \pm 2.64^{\mathrm{a}-\mathrm{c}}$ & $42.79 \pm 2.64^{\mathrm{a}-\mathrm{c}}$ & $22.49 \pm 1.83^{\mathrm{a}-\mathrm{c}}$ & $9.40 \pm 0.84^{\mathrm{a}-\mathrm{c}}$ & $2.22 \pm 2.02^{\mathrm{a}-\mathrm{c}}$ \\
mean $\pm \mathrm{SD}$ & & & & & & \\
\hline
\end{tabular}

${ }^{\mathrm{a}} \mathrm{P}<0.05$ vs. single irradiation group; ${ }^{\mathrm{b}} \mathrm{P}<0.05$ vs. curcumin + irradiation group; ${ }^{\mathrm{c}} \mathrm{P}<0.05$ vs. cisplatin + irradiation group. $\mathrm{SD}$, standard deviation.

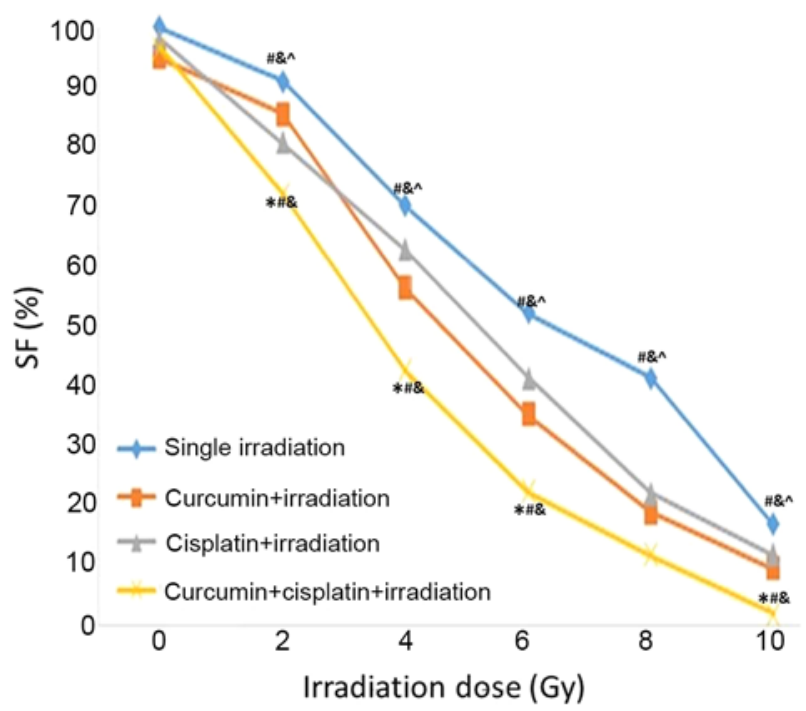

Figure 2. Cell survival curve based on the multi-target single-hit model. SF, surviving fraction. ${ }^{*} \mathrm{P}<0.05$ vs. single irradiation group. ${ }^{*} \mathrm{P}<0.05$ vs. curcumin + irradiation group, ${ }^{\&} \mathrm{P}<0.05$ vs. cisplatin + irradiation group. ${ }^{\wedge} \mathrm{P}<0.05$ vs. curcumin + irradiation + irradiation group.

cisplatin + irradiation, and curcumin + cisplatin + irradiation groups following treatment for $48 \mathrm{~h}$ were $0.47 \pm 0.04,0.41 \pm 0.04$ and $0.23 \pm 0.04$, respectively, which were significantly lower compared with the single irradiation group $(0.59 \pm 0.05$; $\mathrm{P}<0.05)$. The level of EGFR expression in the curcumin + cisplatin and irradiation group was lower compared with the curcumin + irradiation and cisplatin + irradiation groups ( $\mathrm{P}<0.05$; Fig. 5).

\section{Discussion}

As the results of the present study demonstrated, treatment with curcumin was able to inhibit the viability of humanized NSCLC A549 cells, and that this inhibitory effect was concentration- and time-dependent, which was consistent with the results of previous studies $(9,10)$. In addition, curcumin has a notable inhibitory effect on other tumors including brain tumors (11), therefore indicating the broad anti-tumor effect of curcumin. In order to control the cytotoxicity of curcumin during radiotherapy (12), lower doses of curcumin that did not exhibit marked cytotoxicity were selected for
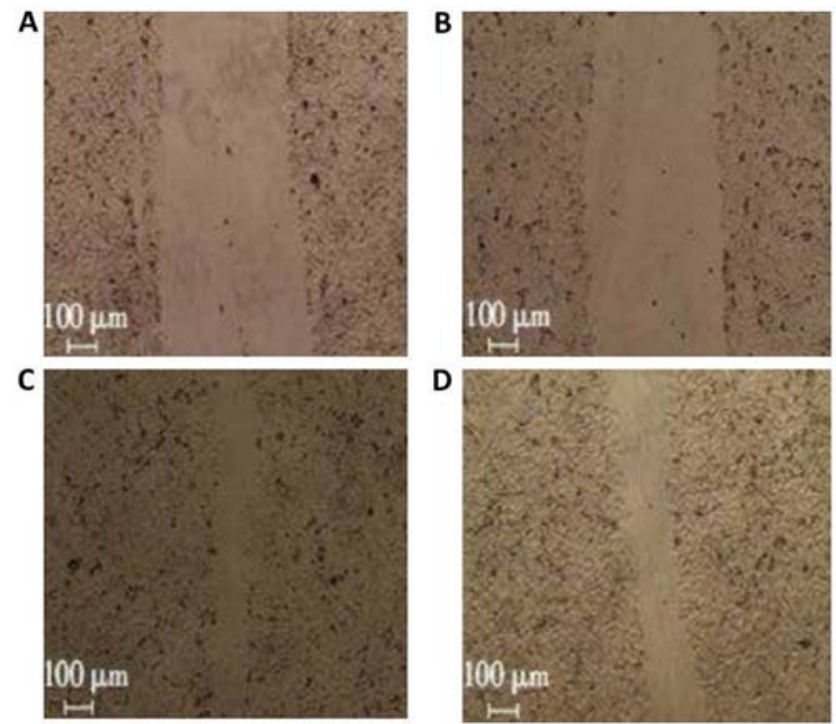

Figure 3. Migration assay of A549 cells in four treatment groups following 24 h. (A) Curcumin + cisplatin + irradiation; (B) cisplatin + irradiation group; (C) curcumin + irradiation group and (D) single irradiation group.

subsequent experiments. The cell survival curve of the A549 cells revealed that the SF irradiation dose increased with an exponential-reducing manner, particularly in the dose range of 6-10 Gy and the cell survival curve which indicated that A549 cells may exhibit resistance to radiation and have the capacity to undergo DNA repair when exposed to sub-lethal damage.

The present study also indicated that treatment with curcumin or cisplatin may be able to promote A549 cells death following X-ray irradiation. It was demonstrated that the inhibitory effect of using a combination of curcumin and cisplatin was more effective compared with the treatment of curcumin or cisplatin alone. The SF value of curcumin + cisplatin + irradiation was lower (SER, 1.96) compared with that of irradiation and treatment with either curcumin (SER, 1.24) or cisplatin alone (SER, 1.31), which indicates a reduced resistance to radiation. Therefore, these findings indicate that treatment with a combination of curcumin and cisplatin was able to have an evident radiosensitization effect on A549 cells cultured in vitro.

Invasion and metastasis are the main causes of therapeutic failure in lung cancer (13), and radiotherapy is used 

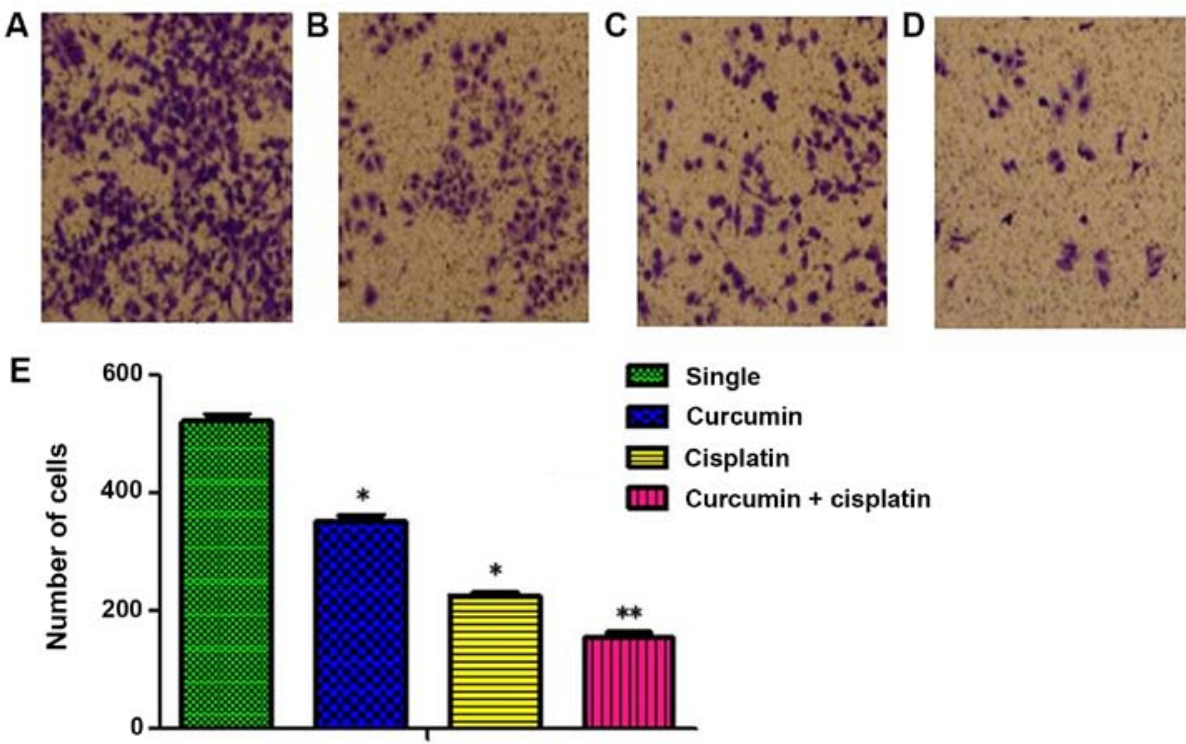

X-ray irradiation

Figure 4. Invasion assay of A549 cell in four treatment groups following 24 h. (A) Single irradiation group; (B) curcumin + irradiation group; (C) cisplatin + irradiation group and (D) curcumin + cisplatin + irradiation group. (E) Cell number in different groups after X-ray irradiation. Magnification, x200. Differences between multiple groups were compared using one-way analysis of variance with Tukey's test. ${ }^{*} \mathrm{P}<0.05,{ }^{* *} \mathrm{P}<0.01$ vs. single irradiation group.

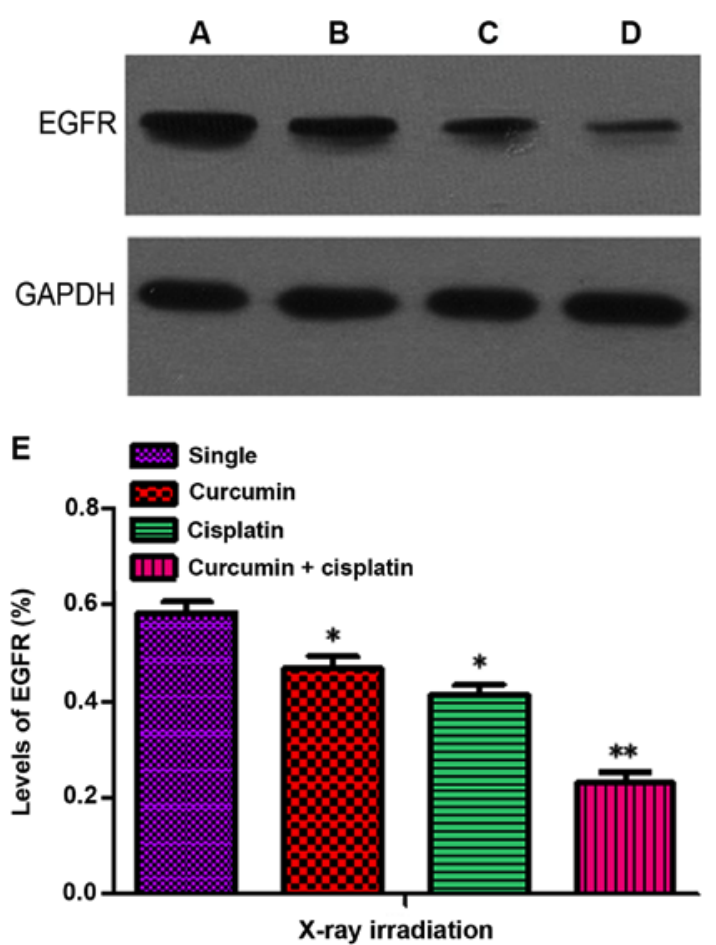

Figure 5. EGFR expression following $24 \mathrm{~h}$. (A) Single irradiation group; (B) curcumin + irradiation group; (C) cisplatin + irradiation group and (D) curcumin + cisplatin +irradiation group. (E) Quantitative evaluation of EGFR level by western blotting after X-ray irradiation. Differences between multiple groups were compared using one-way analysis of variance with Tukey's test. ${ }^{*} \mathrm{P}<0.05,{ }^{* *} \mathrm{P}<0.01$ vs. single irradiation group. EGFR, epidermal growth factor receptor.

for treating metastatic lesions of lung cancer. Therefore, the present study investigated the effects of curcumin + cisplatin treatment on A549 cells in vitro to evaluate the radiosensitization effects of curcumin + cisplatin. The results demonstrated that treatment with a combination of curcumin and cisplatin was able to increase the inhibitory effect of X-ray irradiation on the migration and invasion of A549 cells, which is marked by a reduced migration distance and a reduced number of invaded cells in the curcumin + cisplatin group, compared with the single irradiation group. These results indicate that treatment with curcumin + cisplatin was able to have an overall radiosensitization effect on A549 cells and therefore may be able to inhibit proliferation, invasion and metastasis of lung cancer cells.

In recent years, EGFR has been demonstrated to have an important role in mediating resistance to radiation in malignant tumors $(14,15)$, and an association between high EGFR expression and increased resistance of radiation has been revealed (16). The mechanism of EGFR-mediated radiation resistance is complex and may be associated with self-healing when tumor cells become damaged (17). Therefore, reducing the level of EGFR expression is a common mechanism of action for sensitizers.

The present study indicated that curcumin was able to increase the inhibitory effects of X-ray irradiation on the expression of EGFR, and the inhibitory effect was increased when cells were treated with a combination of curcumin and cisplatin, compared with the single irradiation group. In view of the signaling pathway associated with EGFR, further experiments with a combination of curcumin and cisplatin on the associated signaling pathway should be conducted.

In conclusion, treatment with a combination of curcumin and cisplatin was able to exert radiosensitization effects on A549 cells and was able to inhibit the A549 cell proliferation, and invasion and migration of the tumor. The mechanism of action of curcumin and cisplatin may be associated with the inhibition of EGFR-associated signaling pathways. Therefore, treatment with a combination of curcumin and cisplatin may have promising prospects in increasing the effects of radiotherapy on NSCLC. 


\section{Acknowledgements}

Not applicable.

\section{Funding}

No funding was received.

\section{Availability of data and materials}

The datasets used and/or analyzed during the present study are available from the corresponding author on reasonable request.

\section{Authors' contributions}

SL and YC produced substantial contributions to conception and design, acquisition of data, and analysis and interpretation of data. ZS was involved in drafting the manuscript, revising it critically for important intellectual content and made substantial contributions to conception and design, acquisition of data and analysis and interpretation of data. SL provided final approval of the version to be published.

\section{Ethics approval and consent to participate}

Not applicable.

\section{Patient consent for publication}

Not applicable.

\section{Competing interests}

The authors declare that they have no competing interests.

\section{References}

1. Zhang NN: Investigation on target therapy and resistance mechanism in non-small cell lung cancer. PhD dissertation, Peking Union Med College, Beijing, China, 2016.

2. Zhao H, Gu J, Hua F, Xu H, Li L, Yang B, Han Y, Liu S and Hong S: A meta-analysis of the timing of chest radiotherapy in patient with limited-stage small cell lung cancer. Zhongguo Fei Ai Za Zhi 13: 892-897, 2010 (In Chinese).

3. Kimple RJ: Strategizing the clone wars: Pharmacological control of cellular sensitivity to radiation. Mol Interv 10: 341-353, 2010.
4. Kang SN, Wang ZC and Li YB: Curcumin protects human malpighian cell by oxidative damage of ultraviolet light. Chin J Gerontol 28: 1688-1690, 2008 (In Chinese)

5. Huang HY, Wang Y, Chen FX, Liu JQ, Zhou ZH and Zhang J: Study on the induction of human tolerogenic denfritic cells by curcumin. Chin J Immunol 27: 611-615, 2011 (In Chinese).

6. Song LP: Research progress of curcumin treating atherosclerosis cardiovascular disease. Med Sci J Cent South China 41: 417-421, 2013 (In Chinese).

7. Lev-Ari S, Starr A, Katzburg S, Berkovich L, Rimmon A, Ben-Yosef R, Vexler A, Ron I and Earon G: Curcumin induces apoptosis and inhibits growth of orthotopic human non-small cell lung cancer xenografts. J Nutr Biochem 25: 843-850, 2014.

8. Li X, Xie W, Xie C, Huang C, Zhu J, Liang Z, Deng F, Zhu M, Zhu W,Wu R, et al: Curcumin modulates miR-19/PTEN/AKT/p53 axis to suppress bisphenol A-induced MCF-7 breast cancer cell proliferation. Phytother Res 28: 1553-1560, 2014

9. Hong JM, Park CS, Nam-Goong IS, Kim YS, Lee JC, Han MW, Choi JI, Kim YI and Kim ES: Curcumin enhances docetaxel-induced apoptosis of $8505 \mathrm{C}$ anaplastic thyroid carcinoma cells. Endocrinol Metab (Seoul) 29: 54-61, 2014.

10. Cao H, Diao LM and Xia D: Effects of curcumin combined with cisplatin on the proliferation and apoptosis of human lung cancer cell line A549 in vitro. Med J Wuhan Univ 29: 213-217, 2008.

11. Klinger NV and Mittal S: Therapeutic potential of curcumin for the treatment of brain tumors. Oxid Med Cell Longev 2016: $9324085,2016$.

12. Jamil QUA, Jaerapong N, Zehl M, Jarukamjorn K and Jäger W: Metabolism of curcumin in human breast cancer cells: Impact of sulfation on cytotoxicity. Planta Med 83: 1028-1034, 2017.

13. Hassan WA, Yoshida R, Kudoh S, Hasegawa K, Niimori-Kita K and Ito T: Notch1 controls cell invasion and metastasis in small cell lung carcinoma cell lines. Lung Cancer 86: 304-310, 2014.

14. Eke I, Sandfort V, Storch K, Baumann M, Röper B and Cordes N: Pharmacological inhibition of EGFR tyrosine kinase affects ILK-mediated cellular radiosensitization in vitro. Int J Radiat Biol 83: 793-802, 2007.

15. Eke I, Schneider L, Förster C, Zips D, Kunz-Schughart LA and Cordes N: EGFR/JIP-4/JNK2 signaling attenuates cetuximab-mediated radiosensitization of squamous cell carcinoma cells. Cancer Res 73: 297-306, 2013.

16. Rego RL, Foster NR, Smyrk TC, Le M, O'Connell MJ, Sargent DJ, Windschitl $\mathrm{H}$ and Sinicrope FA: Prognostic effect of activated EGFR expression in human colon carcinomas: Comparison with EGFR status. Br J Cancer 102: 165-172, 2010.

17. Boross $\mathrm{P}$, Lohse $\mathrm{S}$, Nederend $\mathrm{M}$, Jansen JH, van Tetering $\mathrm{G}$, Dechant M, Peipp M, Royle L, Liew LP, Boon L, et al: IgA EGFR antibodies mediate tumour killing in vivo. EMBO Mol Med 5: 1213-1226, 2013

This work is licensed under a Creative Commons Attribution-NonCommercial-NoDerivatives 4.0 International (CC BY-NC-ND 4.0) License. 